\title{
Development of a modified standard apparatus for heat transfer measurements in highly viscous binary fluids
}

\author{
Ann-Christin Fleer ${ }^{1}$ (D) Markus Richter ${ }^{2} \cdot$ Roland Span $^{1}$
}

Received: 20 April 2020 / Accepted: 18 January 2021 / Published online: 1 February 2021

(C) The Author(s) 2021

\begin{abstract}
A modified so-called standard apparatus for heat transfer measurements in highly viscous binary fluids has been developed. It covers a viscosity range from $0.2 \mathrm{mPa} \cdot \mathrm{s}$ up to $1000 \mathrm{~Pa} \cdot \mathrm{s}$ and is designed for measurements over a temperature range from 273 to $423 \mathrm{~K}$. Concept and setup of the apparatus are described in detail, and uncertainties of the different elements of the measurement chain are discussed. An estimation for the total uncertainty of the heat transfer coefficient is $\Delta \alpha / \alpha=16 \%(k=2)$. Model mixtures consisting of polydimethylsiloxane of three different viscosities and $n$-pentane were chosen. The composition of the fluid is calculated with the refractive index and the temperature; a corresponding correlation was developed. $N$-pentane evaporates on a heated test tube, which is exchangeable and thus enables the investigation of the influence of the surface structure and of the material on the heat transfer coefficient. The design of the test tubes has been adapted to very high temperatures on the tube surface. The effects of the mandatory remixing of the two components on the heat transfer coefficient have been investigated. The modified standard apparatus was validated with pure $n$-pentane and the data was compared to published data in literature.
\end{abstract}

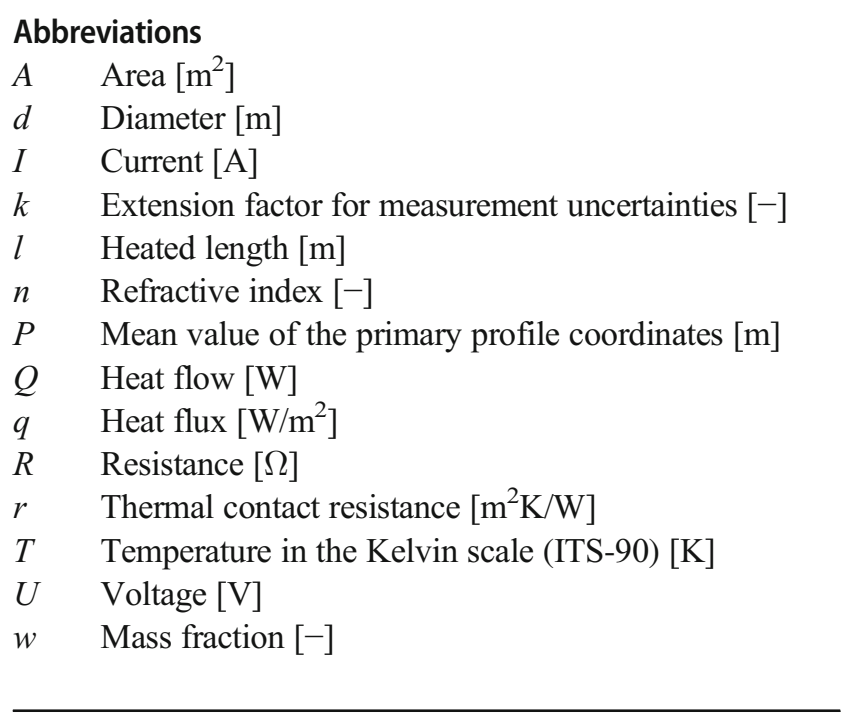

Roland Span

roland.span@thermo.rub.de; http://orcid.org/0000-0002-8350-8285

Ann-Christin Fleer

http://orcid.org/0000-0001-8471-100X

Markus Richter

http://orcid.org/0000-0001-8120-5646

1 Thermodynamics, Ruhr University Bochum, 44801 Bochum, Germany

2 Applied Thermodynamics, Chemnitz University of Technology, 09107 Chemnitz, Germany $\alpha \quad$ Heat transfer coefficient $\left[\mathrm{W} / \mathrm{m}^{2} \mathrm{~K}\right]$

$\Delta \quad$ Difference $[-]$

$\eta \quad$ Dynamic viscosity $[\mathrm{Pa} \cdot \mathrm{s}]$

$\lambda$ Thermal conductivity $[\mathrm{W} / \mathrm{mK}]$

$\rho \quad$ Density $\left[\mathrm{kg} / \mathrm{m}^{3}\right]$

$\delta \quad$ Partial differential [-]

$\sigma \quad$ Standard deviation [-]

o Outer [-]

a Unfiltered arithmetic mean [-]

exp Experimental [-]

\section{Introduction}

Devolatilization of highly viscous fluid mixtures is a key issue in the production of polymer products. During this process side products of the polymerization such as unreacted monomers, oligomers and solvents are separated from the final product. This can be done with dynamic equipment such as extruders or different types of evaporators. Legislation, strict environmental requirements, and product requirements limit the allowable quantity of side products. To meet these demands, to improve the quality of the final product, and to increase energy efficiency it is crucial to understand the involved heat transfer mechanisms and to develop correlations for the calculation of heat transfer coefficients in highly viscous mixtures. To build a data base for the development of correlations and to identify effects of 
different parameters such as temperature, composition, and viscosity, systematic heat transfer measurements for pool boiling heat transfer in highly viscous mixtures are required. Yet, no literature on this topic is publicly available.

Experimental investigations for flow boiling in a vertical tube show that heat transfer mechanisms in fluids with high viscosity are different to those in fluids with low viscosity such as refrigerants or water [1]. Discrepancies between these experimental results and common correlations for the calculation of the heat transfer coefficient were observed $[1,2]$. Heat transfer in mixtures, especially in refrigerant/oil mixtures, is a related research field. Investigations show that even small amounts of oil change the physical properties of the refrigerant, which leads to a significant change in boiling behavior [3]. In general heat transfer coefficients are reduced by introduction of a second component. This is also true for zeotrope binary refrigerant/oil mixtures with more than 3 wt.-\% oil [3, 4]. The lower boiling component evaporates primarily and is enriched in the emerging bubble. Consequently, the composition close to the heating element changes and with it the thermophysical properties, e.g. density, viscosity, and surface tension of the mixture. This influences the departure radius of bubbles, which also affects the convective heat transfer [3]. There are no experimentally determined heat transfer coefficients published for refrigerant/oil mixtures with more than 10 wt.-\% oil [5].

Against this background, a modified so-called standard apparatus was developed [6] to improve the fundamental understanding of heat transfer processes in highly viscous mixtures and to establish a database for correlation needs. The primary goal is to identify the influence of viscosity, mass fraction of the volatile component, boiling temperature, and surface characteristics of the test tube on the heat transfer coefficient.

In the present work, the modified standard apparatus for pool boiling heat transfer measurements is described. A model mixture consisting of polydimethylsiloxane (PDMS) of different viscosities and $n$-pentane was chosen. During a measurement series $n$-pentane evaporates on a heated test tube, is condensed, and remixed with the PDMS. Three challenges of pool boiling experiments with highly viscous mixtures are discussed: high temperatures on the test tube, impact of the remixing of the components and the inline measurement of the fluid's composition. Results obtained for the heat transfer in highly viscous mixtures are presented in a second article submitted in parallel [7].

\section{Apparatus description}

\subsection{Challenges in pool boiling heat transfer measurements in highly viscous mixtures}

The design of the modified standard apparatus is based on a standard apparatus for measurements of pool boiling heat transfer in refrigerants [8]. Three basic challenges were identified for measurements of pool boiling heat transfer in highly viscous mixtures:

1. The heat transfer in highly viscous mixtures is inhibited, which means that the heat is dissipated less effectively. This leads to very high temperatures on the surface of the heated test tube. Melting of the soft solder commonly used to improve the thermal contact inside the test tube and its damage could be a consequence.

Solution: the construction of the test tube is adapted to a higher temperature resistance. Thermal grease does not melt until very high temperatures are reached. Thus, the use of thermal grease instead of soft solder allows higher temperatures on the tube surface and accordingly higher heat fluxes in highly viscous mixtures (see Sect. 2.4).

2. The composition of the mixture needs to be determined and controlled during a measurement series to have authoritative data.

Solution: refractometry was found to be the ideal way to measure the composition of the mixture inline. To calculate the composition by the measured refractive index and temperature, a correlation between the three properties needed to be developed and calibrated. A test loop has been built, and calibration measurements were conducted. A correlation based on this data was developed (see Sect. 2.8).

3. The volatile component $n$-pentane evaporates on the heated test tube; the PDMS concentration in the vapor phase is well below any detection threshold. The components need to be remixed continuously to avoid a change in the composition of the mixture in the pool. The remixing process causes a flow (forced convection). The influence of this flow should be minimized considering the aim to measure at pool boiling conditions.

Solution: the influence of the flow on the heat transfer coefficient and the change in the composition of the mixture were experimentally determined. The ideal compromise in the settings between least forced convection and stable composition had to be found (see Sect. 3.2).

\subsection{Design of the apparatus}

Figure 1 shows a schematic diagram of the modified standard apparatus, where the evaporator is the core of the apparatus. The volatile component, $n$-pentane, evaporates on the heated test tube and rises to a water-cooled condenser. The condensed $n$-pentane is collected in a reservoir. The filling level in the reservoir is measured using a differential-pressure indicator (type 1199, 


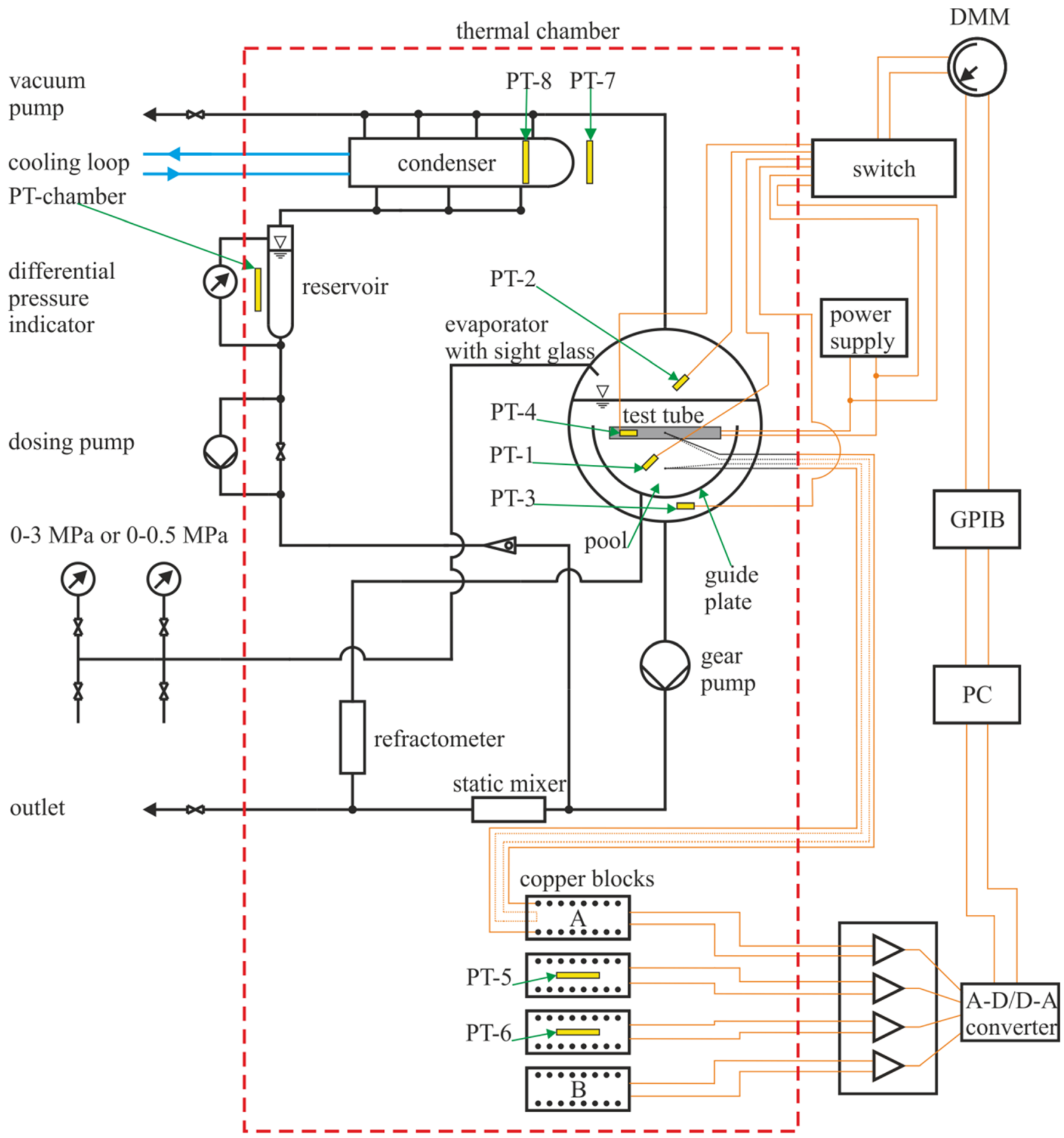

Fig. 1 Schematic diagram of the modified standard apparatus for pool boiling heat transfer measurements. The dashed line symbolizes the thermal chamber

Rosemount, USA). By means of a dosing pump (M910S, LEWA GmbH, Germany), the $n$-pentane is pumped to the static mixer (CSE-X/8, Fluitec, Switzerland). Inside the evaporator, the depleted PDMS flows over a guide plate and is pumped to the static mixer by a gear pump (CHEM 25,6-3, Witte Pumps, Germany) where it is mixed with the condensed $n$-pentane. Downstream of the static mixer, the refractive index of the mixture is measured by a refractometer (PIOX-R400, flexim,
Germany). The composition is calculated by a correlation that considers the refractive index and the temperature. Ultimately, the mixture is pumped back into the evaporator, which is equipped with a sight glass to allow visual observations of the boiling behavior. At the lowest point of the apparatus, an outlet valve is installed to drain the apparatus after a measurement series. To evacuate the whole system and to reduce the amount of solved gases in the PDMS, a vacuum pump is installed. 
As shown in Fig. 1, the insulated apparatus is mounted inside a thermal chamber (inner dimensions: $180 \mathrm{~cm} \times 160 \mathrm{~cm} \times 90 \mathrm{~cm}$ ), which guarantees a static temperature $( \pm 0.3 \mathrm{~K})$ and which can be heated up to $T=423 \mathrm{~K}$ by four heating elements in a ventilation conduit. The temperature measurement is conducted with nine platinum resistance thermometers (Pt-100 $\Omega$ ) and several $\mathrm{NiCr} /$ $\mathrm{Ni}$ - thermocouples (type $\mathrm{K}$ class 1 ). The locations of the Pt$100 \Omega$ (PT-1 to PT-8, PT-chamber) are illustrated in Fig. 1. The platinum resistance thermometers are placed at representative spots inside the thermal chamber, in the pool and in two copper blocks at the bottom of the thermal chamber. The thermocouples are installed at different heights in the pool to measure the temperature gradient within the pool. The temperature gradient between the test tube and the boiling liquid is measured by 24 thermocouples: 12 are located inside the test tube and another 12 are placed $40 \mathrm{~mm}$ below the tube at the bottom of the pool. Their reference junctions are located in the two copper blocks. The pressure is measured with two pressure transducers (type Honeywell Super TJE, AP 111 , Sensotec, USA) with a range of 0 to $0.5 \mathrm{MPa}$ and 0 to $3 \mathrm{MPa}$. To reduce the impact of high temperatures, the transducers are installed outside the thermal chamber. The measurement electronics are housed in a 19" instrument rack.

\subsection{Materials}

PDMS is commercially available in a wide range of viscosities. For the experiments PDMS Baysilone M10k, PDMS Baysilone M100k and PDMS Baysilone M1000k (Kurt Obermeier GmbH \& Co., Bad Berleburg, Germany) with the viscosities $\eta_{\text {PDMS M10k }}=9.7 \mathrm{~Pa} \cdot \mathrm{s}, \eta_{\text {PDMS }}$ M100k $=$ 97.0 Pa·s, and $\eta_{\text {PDMS M1000k }}=970.0 \mathrm{~Pa} \cdot \mathrm{s}$ at standard temperature $T=298.15 \mathrm{~K}$ is used [9]. Its vapor pressure is very low with about $10 \mathrm{~Pa}$ at 293.15 K [9]. At low shear rates (up to $10^{3} \mathrm{~s}^{-1}$ ) and low viscosity (up to $10 \mathrm{~Pa} \cdot \mathrm{s}$ ), PDMS shows a Newtonian behavior [9]. With increasing viscosity, structural viscosity becomes relevant at lower shear rates; the range of Newtonian behavior is shifted to lower shear rates.

$N$-pentane is a perfect solvent for PDMS because it is completely miscible in PDMS. In terms of risk assessment, it performs better than other solvents. Its normal boiling temperature is at $309.21 \mathrm{~K}$ and its vapor pressure is $0.057 \mathrm{MPa}$ at 293.15 K [10]. Due to the high difference in molar mass between $n$-pentane and PDMS, compositions are indicated in weight- $\%$ in this article. In terms of mole fractions, $n$-pentane always is the dominant component. The viscosities of the pure components are calculated with

$\ln \left(\frac{\eta}{\eta_{0}}\right)=A-\frac{B}{\frac{T-273.15}{\mathrm{~K}}+D}$

using $\eta_{0}=1 \mathrm{~Pa} \cdot \mathrm{s}$ and the coefficients listed in Table 1 for PDMS M100k and PDMS M1000K.
Table 1 Empirical coefficients for the calculation of the viscosity of the pure components $n$-pentane, PDMS M100k, and PDMS M1000k [11] and calculated viscosity $\eta$ at standard conditions

\begin{tabular}{llll}
\hline Coefficient & $n$-pentane & M100k & M1000k \\
\hline$A$ & -19.95067 & -4.18166 & -0.27014 \\
$B$ & $-14,059.68$ & -3685.19 & -2213.52 \\
$D$ & 1192.28 & 394.22 & 282.43 \\
$\eta(298.15 \mathrm{~K}, 0.1 \mathrm{MPa})$ & $2.20 \cdot 10^{-4} \mathrm{~Pa} \cdot \mathrm{s}$ & $97.0 \mathrm{~Pa} \cdot \mathrm{s}$ & $970.0 \mathrm{~Pa} \cdot \mathrm{s}$ \\
\hline
\end{tabular}

The coefficients used to calculate the temperature dependence of the viscosity of PDMS M10k are unpublished proprietary information of the manufacturer. However, the temperature dependence of the viscosity of the three pure PDMS is shown in Fig. 2; the viscosity decreases significantly with increasing temperature and there is no qualitative difference between the plots for $\mathrm{M} 10 \mathrm{~K}$ and the other two PDMS.

The viscosity of mixtures is calculated with an empirical equation provided by Bayer Technology Services in an internal report. With an increasing fraction of $n$-pentane, the viscosity of the composition decreases. The exemplary results of calculations at $353 \mathrm{~K}$ are shown in Fig. 3. The viscosity decreases significantly even for small fractions of $n$-pentane.

\subsection{Construction of the test tubes}

The test tubes have an outer diameter $d_{\mathrm{o}}$ of $8 \mathrm{~mm}$ and a heated length $l$ of $180 \mathrm{~mm}$. 12 thermocouples per tube are evenly distributed around the tube radius inside of grooves $1 \mathrm{~mm}$ below the surface. Figure 4 displays a construction drawing of a test tube.

Figure 5 shows a cross section of a test tube used in the present work. Thermal grease with a temperature stability of $1473 \mathrm{~K}$ (TG 20033 Dr. D. Müller GmbH) is used for thermal contacting instead of soft solder to achieve a stable construction of the test tubes and a uniform temperature distribution. The heating element is connected to a DC power supply.

The surface finish of the test tubes is established and analyzed by Prof. A. Luke and her team at the University of Kassel; the corresponding fundamentals are explained in detail in [12]. A polished and a sanded surface finish are chosen to cover a wide range of surface roughness in order to investigate the effect of surface roughness on heat transfer in boiling highly viscous mixtures. The parameters of the polished and sanded copper tubes are given in Table 2, where $P_{\mathrm{a}}$ stands for the unfiltered arithmetical mean of the primary roughness profile [13].

Figure 6 shows sections of the surface topography measurements of the polished and the sanded test tube. The depths and heights of surface structures in the sanded profile are extreme compared to the polished profile. 
Fig. 2 Change in viscosity with respect to the temperature for PDMS M10k, PDMS M100k and PDMS M1000k

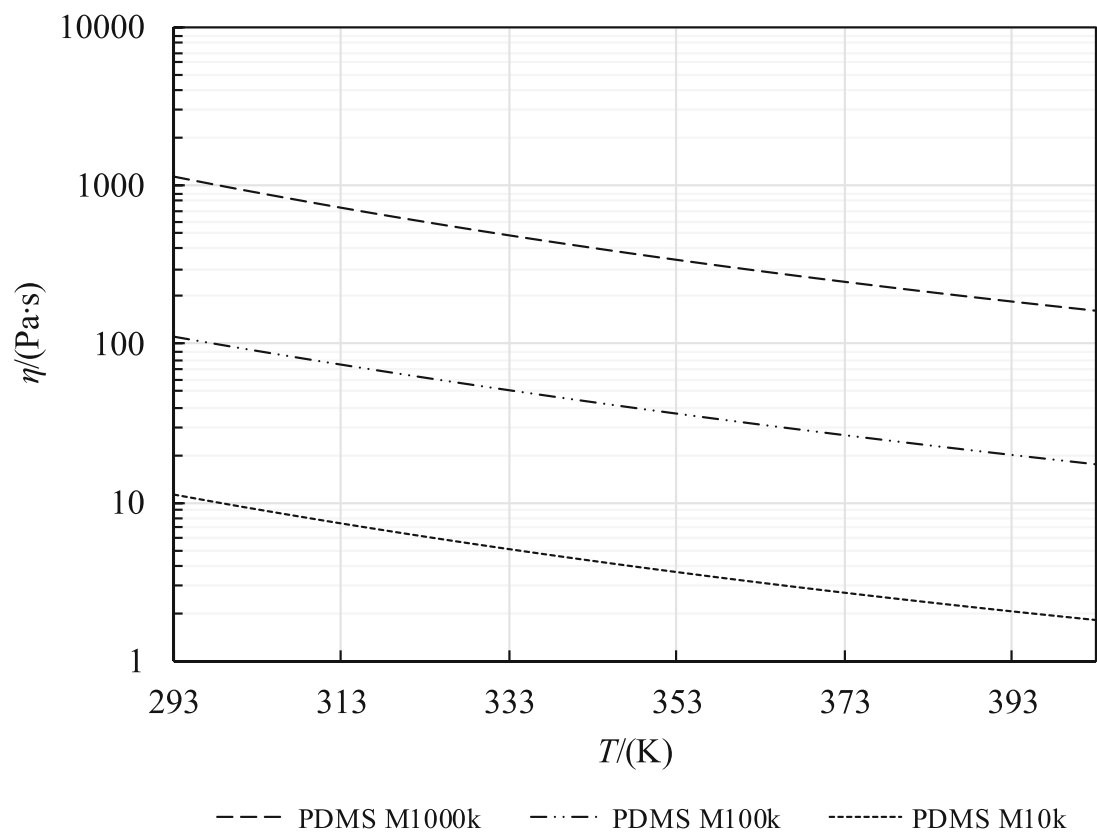

\subsection{Calculation of the heat transfer coefficient}

The heat transfer coefficient $\alpha$ is defined as $\alpha=q / \Delta T=Q /(A$. $\Delta T$ ) with the heat flux $q$, the heat flow $Q$, the heated area $A$ and the superheat $\Delta T\left(\Delta T=\left(T_{\text {surface }}-T_{\text {fluid }}\right)\right.$. The heated area is calculated with $A=d_{\mathrm{o}} \cdot \pi \cdot l$ where $d_{\mathrm{o}}$ is the outer diameter of the tube and $l$ its heated length. The specific heat flux $q$ is calculated with

$q=\frac{\left(U_{\text {tube }}-R_{\text {cold }} \cdot I_{\text {tube }}\right) \cdot I_{\text {tube }}}{A}$

and with

Fig. 3 Change in viscosity plotted over the mass fraction of $n$-pentane for PDMS M10k, PDMS M100k and PDMS M1000k at $353 \mathrm{~K}$
$U_{\text {tube }}=U_{2}\left(\frac{R_{1}}{R_{2}}+1\right)-2 \cdot R_{\text {cold }}\left(\frac{U_{3}}{R_{3}}-\frac{U_{2}}{R_{2}}\right)$,

where $R_{1}$ and $R_{2}$ are high-precision resistors (type $S 71153$, $\mathrm{R}_{1}: 1 \mathrm{k} \Omega$ and $\mathrm{R}_{2}: 100 \mathrm{k} \Omega$, Burster, Germany). The current $I_{\text {tube }}$ is calculated with

$I_{\text {tube }}=\frac{U_{3}}{R_{3}}-\frac{U_{2}}{R_{2}}$

where $\mathrm{R}_{3}$ is a third high-precision resistor (type $1153 \mathrm{~S}, 1 \mathrm{~m} \Omega$, Burster, Germany). The resistance $R_{\text {cold }}$ causes a voltage drop at the inactive end of the heating element and is given by the

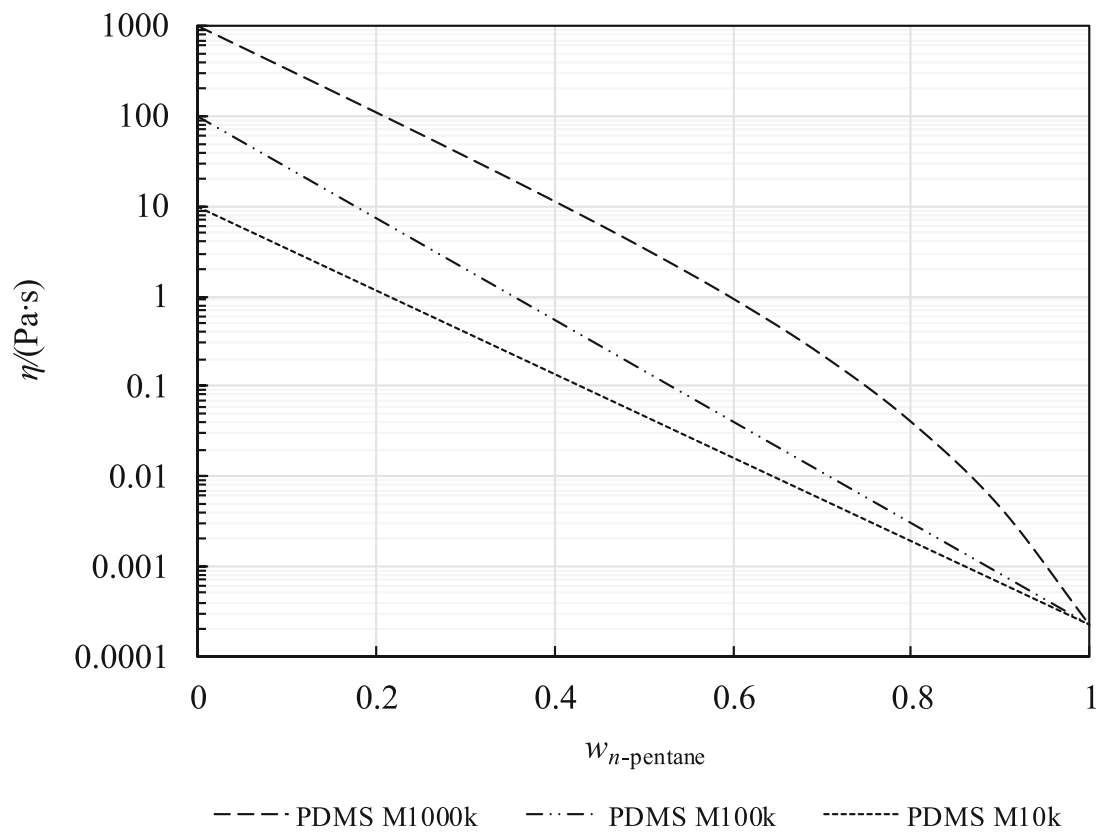



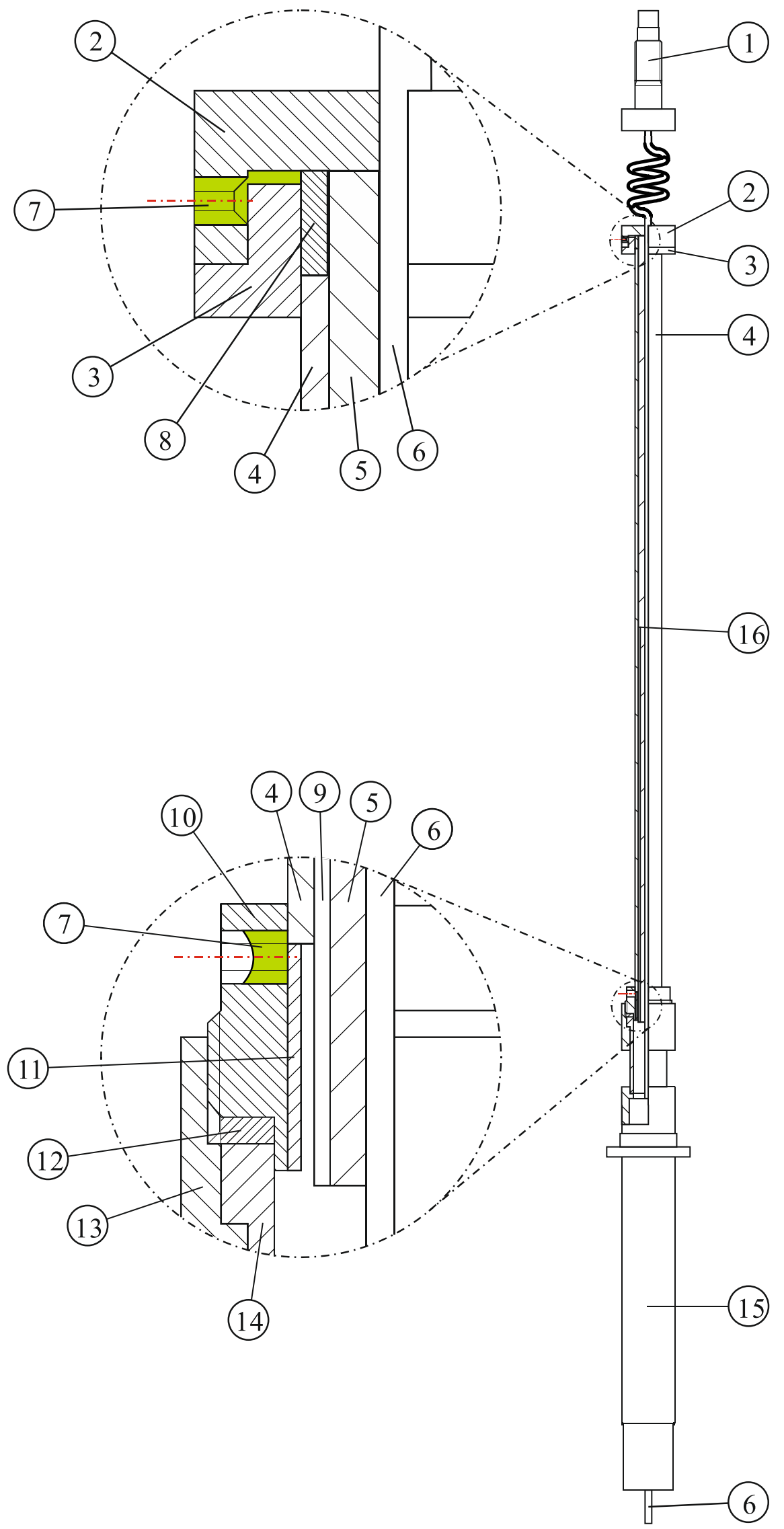

Fig. 4 Construction drawing of a test tube with detailed images of both ends
1 Bolts

2 End piece, left

3 End cap, left

4 Outer pipe

5 Inner pipe

6 Supply line heating conductor

7 Threaded hole

8 Copper sleeve, left

9 Grooves for the TEs

10 End cap, right

11 copper sleeve, right

12 Copper seal

13 Union nut

14 Transition piece

15 Feed-through sleeve

16 Measuring point of the TEs 


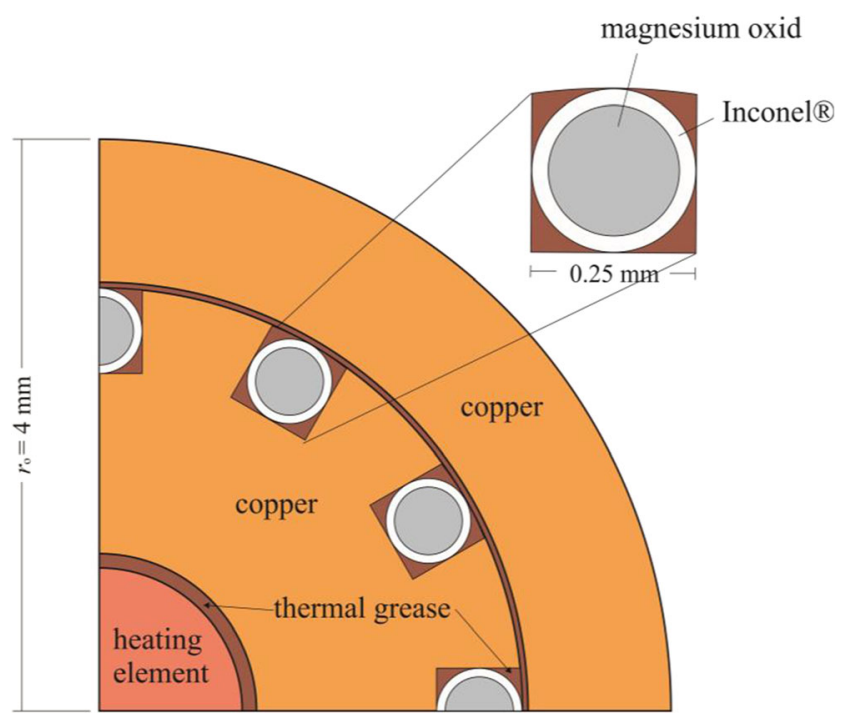

Fig. 5 Cross section of a copper test tube

manufacturer (type ZUZI 20, Thermocoax, France) with $0.0345 \Omega$. Figure 7 shows a circuit diagram of the power supply of the test tube.

The superheat $\Delta T$ between the liquid and the tube surface is measured directly with each of the thermocouples in the test tube. Each thermocouple measures a temperature $1 \mathrm{~mm}$ below the heated surface $\left(T_{\text {surface }}\right)$ and has a reference junction in the bulk of the fluid below the test tube ( $\left.T_{\text {fluid }}\right)$. The experimental superheat values $\Delta T_{\text {exp }}=\left(T_{\text {surface }}-T_{\text {fluid }}\right)$ are calculated with the arithmetical mean of the voltages measured for all 12 thermocouples, corrected by the voltage measured in equilibrium at $q=0\left(\Delta T_{\exp }=0\right) . \Delta T_{\exp }$ is corrected for radial heat conduction within the tube from the groove to the surface (Fig. 5) by $\Delta T=\Delta T_{\exp }-\Delta T_{\mathrm{r} \text {,th }}$ with the temperature correction factor $\Delta T_{\mathrm{r}, \mathrm{th}}$. This factor depends on the construction of the tube and the thermal conductivity $\lambda$ of its material $\left(\lambda_{\text {copper }}=\right.$ $360 \mathrm{~W} / \mathrm{mK}, \lambda_{\text {magnesium oxid }}=50 \mathrm{~W} / \mathrm{mK}, \lambda_{\text {Inconel }}=15 \mathrm{~W} / \mathrm{mK}$, $\lambda_{\text {thermal grease }}=3 \mathrm{~W} / \mathrm{mK}$ ). It is calculated with

$\Delta T_{\mathrm{r}, \mathrm{th}}=q \cdot r_{\mathrm{th}}=q \cdot \frac{1}{2} d_{\mathrm{o}} \cdot \sum \frac{1}{\lambda_{\mathrm{i}}} \ln \left(\frac{d_{\mathrm{i}, \mathrm{o}}}{d_{\mathrm{i}, \mathrm{i}}}\right)$

Table 2 Overview of the geometric and surface characteristics of the polished and sanded copper test tubes

\begin{tabular}{lll}
\hline & Polished test tube & Sanded test tube \\
\hline Surface & Polished by hand & Sanded \\
Material & Copper & Copper \\
Outer diameter $d_{\mathrm{o}}$ & $8 \mathrm{~mm}$ & $8 \mathrm{~mm}$ \\
Heated length $l$ & $180 \mathrm{~mm}$ & $180 \mathrm{~mm}$ \\
Number of thermocouples $n$ & 12 & 12 \\
Roughness $P_{\mathrm{a}}$ & $0.0654 \mu \mathrm{m}$ & $0.71 \mu \mathrm{m}$ \\
\hline
\end{tabular}

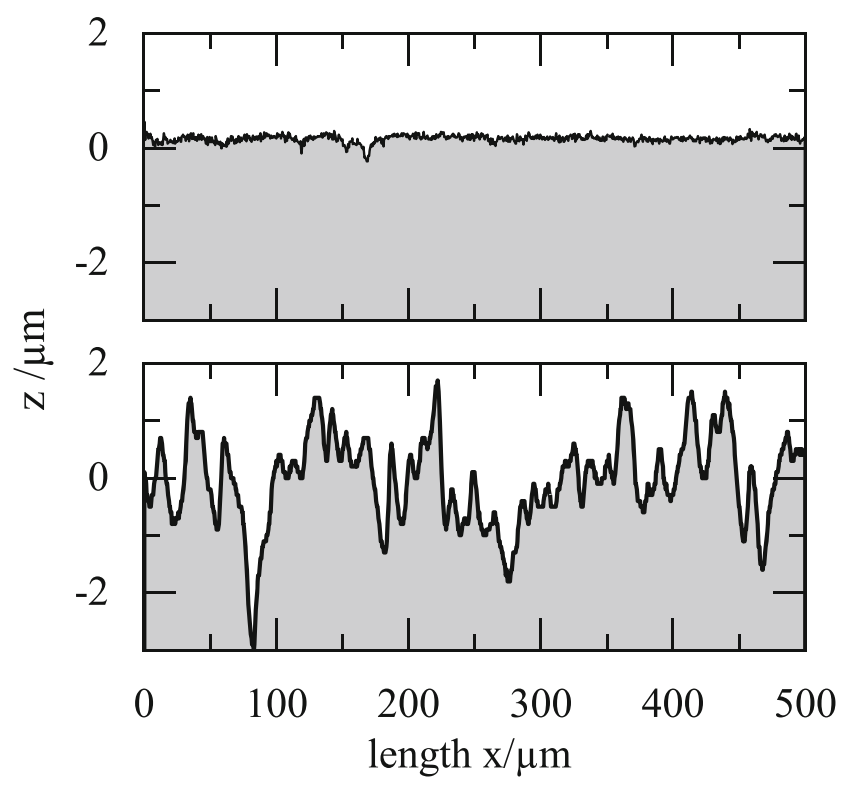

Fig. 6 Section of the surface topographies of the polished and the sanded copper test tube

The thickness of every layer is defined by the outer and inner diameter $d_{\mathrm{i}}$ and $d_{\mathrm{o}}$ of each layer. The copper tubes have a correction factor of $r_{\text {th,copper }}=5.88 \cdot 10^{-5} \mathrm{~m}^{2} \mathrm{~K} / \mathrm{W}$.

\subsection{Uncertainty analysis}

The relative uncertainty of the heat transfer coefficient can in principle be calculated according to

$\frac{\Delta \alpha}{\alpha}=\left[\left(\frac{\Delta(\Delta T)}{\Delta T}\right)^{2}+\left(\frac{\Delta q}{q}\right)^{2}\right]^{1 / 2}$

The sensitivity coefficients of both terms are equal to one. The uncertainty of the composition of the boiling fluid is neglected at this point even though it is considered a significant contribution, because both the

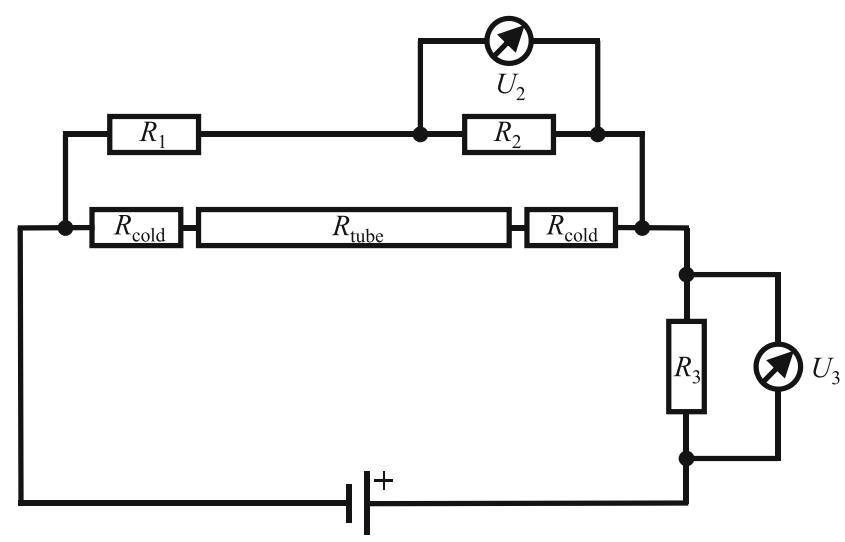

Fig. 7 Circuit diagram of the power supply of the test tube 
Table 3 List of individual relative measurement uncertainties in the determination of the heat transfer coefficient. All uncertainties are estimated at $k=$ 2. Exemplary values are chosen for measurements with $20 \mathrm{wt} .-\% \mathrm{M} 100 \mathrm{k}$ on a polished test tube and $7 \mathrm{wt} .-\%$ M10k on a sanded test tube

\begin{tabular}{|c|c|c|c|c|c|c|c|c|}
\hline$T$ & Evaporator temperature & $\mathrm{K}$ & 321 & & & 378 & & \\
\hline$q$ & Heat flux & $\mathrm{W} / \mathrm{m}^{2}$ & 16,000 & 7997 & 1003 & 100,081 & 50,053 & 10,108 \\
\hline$\Delta T$ & Superheat & $\mathrm{K}$ & 26.65 & 19.37 & 9.0 & 49.61 & 11.34 & 5.40 \\
\hline$\alpha$ & Heat transfer coefficient & $\mathrm{W} / \mathrm{m}^{2} \mathrm{~K}$ & 600 & 412 & 111 & 2017 & 4412 & 1872 \\
\hline \multicolumn{9}{|c|}{ Estimated uncertainty of $q$} \\
\hline 1 & Measurement of heat flow & $\%$ & 0.93 & 0.93 & 0.94 & 0.94 & 0.94 & 0.94 \\
\hline \multirow[t]{2}{*}{2} & Heated area & $\%$ & 0.62 & 0.62 & 0.62 & 0.62 & 0.62 & 0.62 \\
\hline & $\Delta q / q($ at $k=2)$ & $\%$ & 1.12 & 1.12 & 1.13 & 1.13 & 1.13 & 1.13 \\
\hline \multicolumn{9}{|c|}{ Estimated uncertainty of $\Delta T$} \\
\hline 3 & Thermoelectric voltage & $\%$ & 0.45 & 0.45 & 0.45 & 0.45 & 0.45 & 0.45 \\
\hline 4 & Amplifier & $\%$ & 0.12 & 0.12 & 0.12 & 0.12 & 0.12 & 0.12 \\
\hline 5 & Dev. thermoel. voltage curve & $\%$ & 1.15 & 1.15 & 1.15 & 1.15 & 1.15 & 1.15 \\
\hline 6 & Temp. deviation in the pool & $\%$ & 0.43 & 0.60 & 1.30 & 0.23 & 1.02 & 2.14 \\
\hline \multirow[t]{3}{*}{7} & Eccentricity in the test tube & $\%$ & 0.16 & 0.22 & 0.50 & 0.09 & 0.38 & 0.80 \\
\hline & $\Delta T / T($ at $k=2)$ & $\%$ & 1.32 & 1.40 & 1.87 & 1.27 & 1.65 & 2.60 \\
\hline & $\Delta \alpha / \alpha($ at $k=2)$ & $\%$ & 1.73 & 1.79 & 2.18 & 1.69 & 2.00 & 2.83 \\
\hline
\end{tabular}

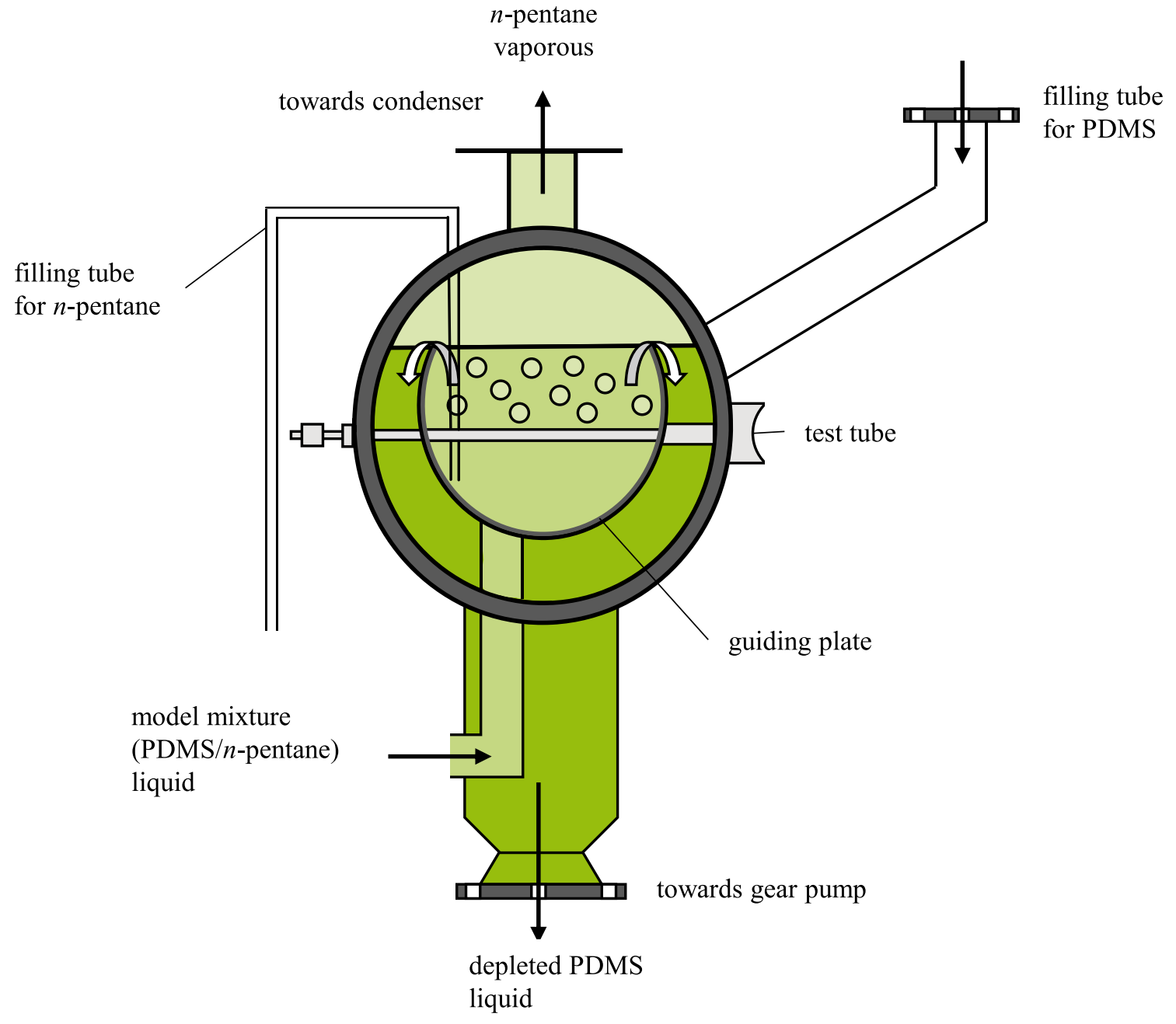

Fig. 8 Schematic diagram of the evaporator and the filling tubes for PDMS and $n$-pentane 


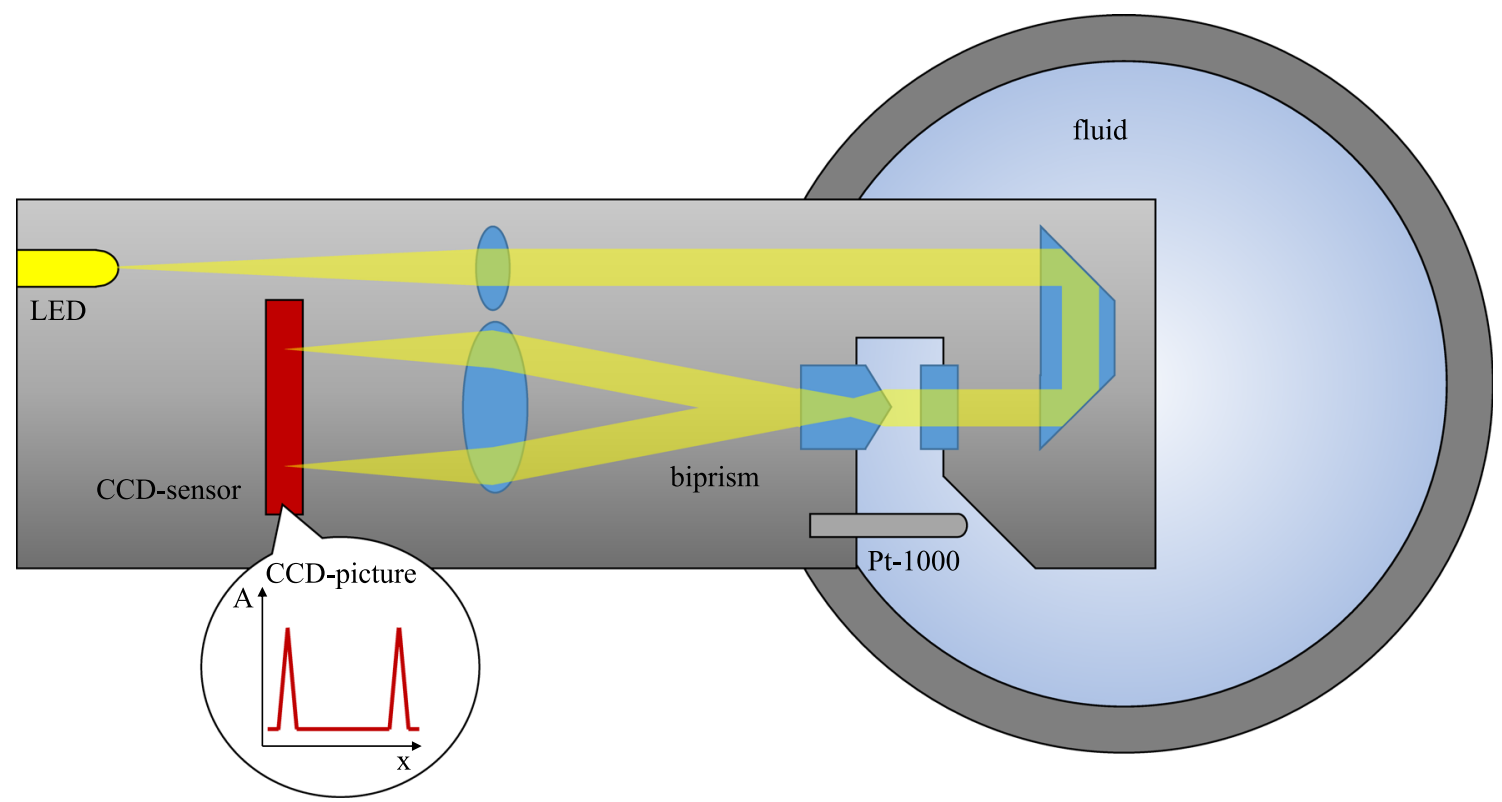

Fig. 9 Schematic diagram of the refractometer PIOX ${ }^{\circledR}$ R400 [14]

corresponding sensitivity coefficient and the magnitude of possible gradients of the composition in the pool are unknown. The same is true for gradients of temperature and pressure of the liquid in the pool, whereby these uncertainty contributions are considered small. The contributions to the combined standard uncertainty by the individual uncertainties of the quantities considered in Eq. (6) are described in the following. The standard uncertainty in heat flux depends on the uncertainties in the heated area and in heat flow, which can be calculated from the uncertainties in the measurement of current and voltage, and from the uncertainty of the resistance of the high-precision resistors. The uncertainty in superheat $\Delta T$ (temperature difference between heated wall and bulk liquid) arises from the individual uncertainties of the thermoelectric voltage, the amplifier, the deviation from the thermoelectric voltage curve, the temperature deviation in the pool and from eccentricities in the test tube. All sources of uncertainty are listed in Table 3. The superheat $\Delta T$ is corrected by the temperature difference measured at $q=0 \mathrm{~W} / \mathrm{m}^{2}$ after every measurement series.

The standard uncertainty in temperature arises from the individual uncertainties of the temperature-measurement chain (calibrated Pt-100 $\Omega$ sensors, resistance bridge, selfheating of the sensor, thermal voltage etc.) and the calibration of the measurement chain. For the temperature range of the modified standard apparatus (293-423 K) the standard uncertainty is estimated to be $0.03 \mathrm{~K}$.

The standard uncertainty in pressure depends on the individual uncertainties of the two calibrated pressure sensors, the uncertainty of the bridge voltage and the supply voltage. For the pressure range of the modified standard apparatus the standard uncertainty is estimated to be $120 \mathrm{~Pa}(0.05-$ $0.16 \mathrm{MPa})$ and $50 \mathrm{~Pa}(0-0.05 \mathrm{MPa})$ respectively.

Despite of this error analysis, no combined uncertainty in the heat transfer coefficient can be given at this point in time - the uncertainty analysis focusing only on the uncertainty of the heat flux and of the measurement of $\Delta T$ does not reflect experimental experience. A major additional source of uncertainty is the composition in the pool close to the test tube, which may deviate from the measured composition in the feed line. Different states of the activation of nucleation sites may contribute to the irreproducibility of experiments as well. However, these influences cannot be quantified at this point in time. Repeated measurements of data points indicate a standard deviation of $\sigma \leq 4 \%$ for the

Table 4 Coefficients for the calculation of the share of $n$-pentane in the mixture

\begin{tabular}{llll}
\hline Coefficients & M10k & M100k & M1000k \\
\hline$A$ & 49.04 & 98.71 & $2.314 \cdot 10^{-7} / \mathrm{K}^{2}$ \\
$B$ & $0.1553 / \mathrm{K}$ & $0.2366 / \mathrm{K}$ & $-4.083 \cdot 10^{-4} / \mathrm{K}$ \\
$C$ & 45.54 & 115.9 & 1.414 \\
$D$ & $5.2161 \cdot 10^{-5} / \mathrm{K}^{2}$ & $9.98 \cdot 10^{-4} / \mathrm{K}^{2}$ & $-2.351 \cdot 10^{-8} / \mathrm{K}^{2}$ \\
$E$ & $0.1024 / \mathrm{K}$ & $0.159 / \mathrm{K}$ & $-1.74 \cdot 10^{-6} / \mathrm{K}$ \\
$F$ & 7.643 & 32 & $-6.374 \cdot 10^{-4}$ \\
$G$ & - & - & $1.283 \cdot 10^{-10} / \mathrm{K}^{2}$ \\
$H$ & - & - & $1.432 \cdot 10^{-9} / \mathrm{K}$ \\
$I$ & - & - & $2.0135 \cdot 10^{-6}$ \\
\hline
\end{tabular}


Fig. 10 a, b $\log , \log \alpha(q)$ - diagrams for nucleate boiling heat transfer of pure $n$-pentane at $T=$ $314.4 \mathrm{~K}$ and $350.4 \mathrm{~K}$. $\square$ Buljina [6] used the modified standard apparatus and a copper tube, $d_{\mathrm{o}}=$ $8 \mathrm{~mm}$, sanded, $R_{\mathrm{a}}=0,66 \mu \mathrm{m} . \Delta$ Kotthoff [17] used a standard apparatus and a copper tube, $d_{\mathrm{o}}=$ $8 \mathrm{~mm}$, sand blasted, $R_{\mathrm{a}}=0,62 \mu \mathrm{m}$
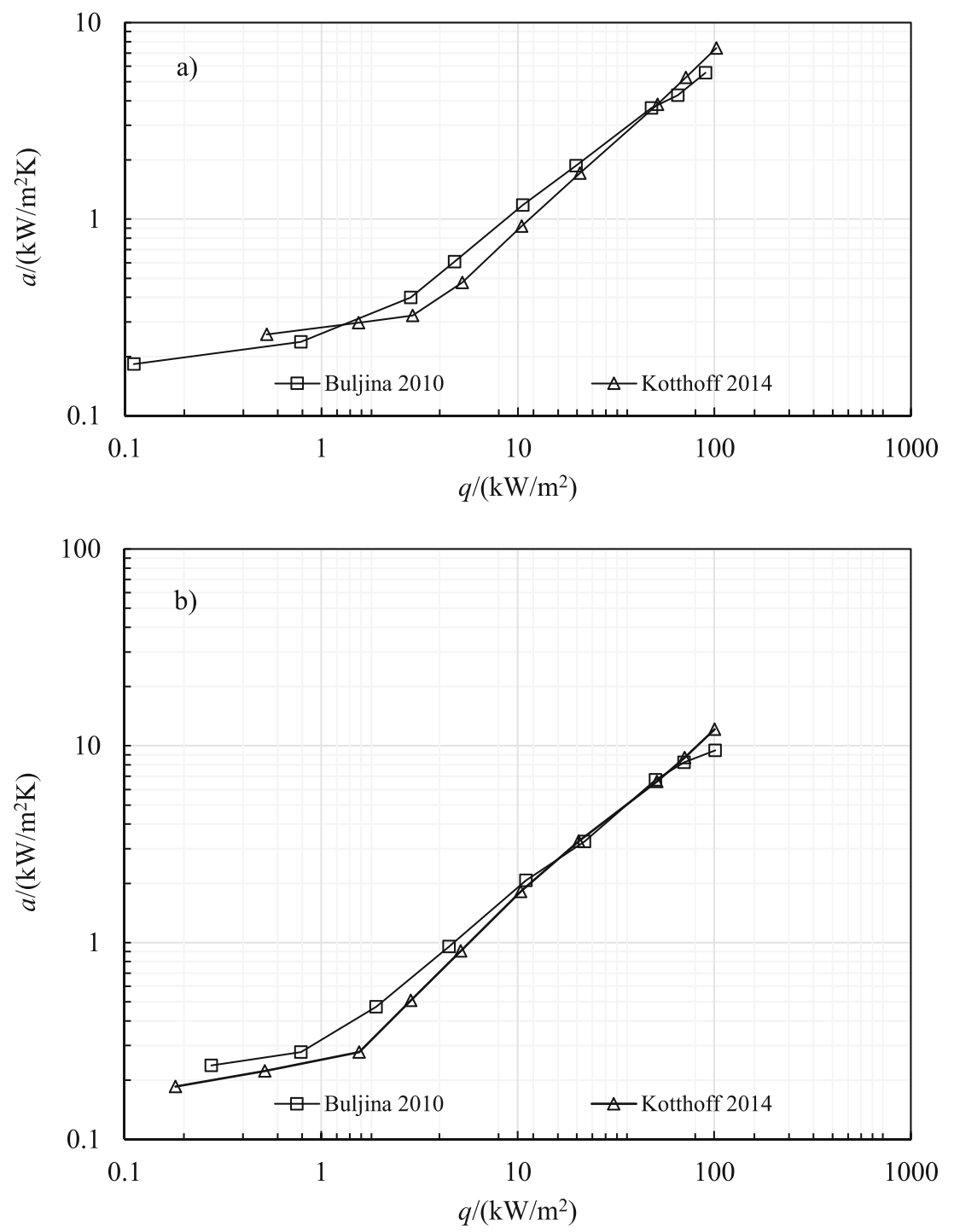

heat transfer coefficient $\alpha$ as a function of heat flux, temperature, composition, and chosen PDMS viscosity. On this basis, a conservative estimation for the total uncertainty in the heat transfer coefficient is $\Delta \alpha / \alpha=16 \%$ at $k=2$.

\subsection{Filling the experimental loop and measurement procedure}

The test tube is cleaned in steps with three different solvents: 4 vol.-\% hydrochloric acid, distilled water and isopropyl alcohol. The tubes are dried with a hot air dryer and then directly installed in the evaporator. Leakages must be eliminated. To produce a model mixture, the corresponding percentage by weight of PDMS is filled in. For PDMS of high viscosities, in particular for PDMS M1000k with $\eta=970 \mathrm{~Pa} \cdot \mathrm{s}$ at $298.15 \mathrm{~K}$, it is helpful to preheat the PDMS to accelerate the filling process. The experimental loop is evacuated by a vacuum pump for at least $24 \mathrm{~h}$ to reduce the amount of gases dissolved in the PDMS. In the next step the low pressure is used to soak $n$-pentane into the experimental loop via a filling tube. The test tube must be covered by fluid. The total filling volume is 12.51 . The evaporator and the filling tubes are shown schematically in Fig. 8.

Once the filling process is completed, the thermal chamber is heated to the equilibrium value belonging to the pressure
Table 5 Calculated average velocities at the entrance of the pool and on the test tube level at specific mass flows

\begin{tabular}{lllll}
\hline Mass flow & $4 \mathrm{~kg} / \mathrm{h}$ & $8 \mathrm{~kg} / \mathrm{h}$ & $12 \mathrm{~kg} / \mathrm{h}$ & $16 \mathrm{~kg} / \mathrm{h}$ \\
\hline Velocity at entrance to the pool & $0.56 \mathrm{~mm} / \mathrm{s}$ & $1.68 \mathrm{~mm} / \mathrm{s}$ & $1.68 \mathrm{~mm} / \mathrm{s}$ & $2.22 \mathrm{~mm} / \mathrm{s}$ \\
Velocity at test tube level & $0.05 \mathrm{~mm} / \mathrm{s}$ & $0.09 \mathrm{~mm} / \mathrm{s}$ & $0.13 \mathrm{~mm} / \mathrm{s}$ & $0.18 \mathrm{~mm} / \mathrm{s}$ \\
\hline
\end{tabular}


Fig. $11 \log , \log \alpha(q)$ - diagram for boiling heat transfer of $73 \mathrm{wt}$.$\%$ PDMS M100k in $n$-pentane at $T=316 \mathrm{~K}$ at different mass flows on a polished copper tube

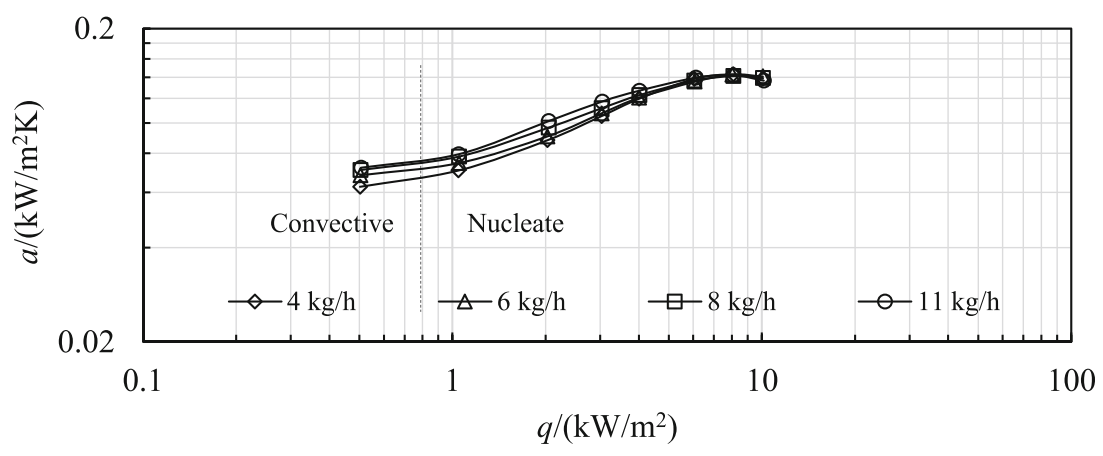

chosen for the respective measurement series. To reduce thermal stress on the material, the temperature increase is limited to $6 \mathrm{~K}$ per hour. A very high heat flux is set for $3 \mathrm{~h}$ to activate all nucleation sites on the test tube. In general, the measurements are carried out from high to low heat fluxes.

\subsection{Composition analysis}

The modified standard apparatus is equipped with a refractometer (PIOX ${ }^{\circledR}$ R400, flexim, Germany). When calibrated properly considering both the temperature and composition dependence of the refractive index, refractometry is a reliable method for in-situ measurements of the mixture composition. The refractometer measures the refractive index $n$ and the temperature. Bubbles or turbidity do not influence the measured data. A schematic diagram of the used refractometer is shown in Fig. 9.

Based on published data $[15,16]$ a separate correlation for each type of PDMS was developed to calculate the share of $n$ pentane in weight-\% in the mixture (see Eq. (7) and (8)). The mass fraction of $n$-pentane in mixtures with M10k and M100k may be calculated as

$$
W_{n-\text { pentane }} / \%=A-B \cdot T-C \cdot n+D \cdot T^{2}+E \cdot T \cdot n+F \cdot n^{2}
$$

and in mixtures with M1000k as

Fig. $12 \log , \log \alpha(q)$ - diagram for boiling heat transfer of $73 \mathrm{wt}$.$\%$ PDMS M100k in $n$-pentane at $T=349 \mathrm{~K}$ at different mass flows on a polished copper tube

$$
\begin{aligned}
& W_{n-\text { pentane }} / \% \\
& =\frac{-0.5(F+E \cdot T+D \cdot T 2)}{I+H \cdot T+G \cdot T 2}-\left[0.25\left(\frac{F+E \cdot T+D \cdot T 2}{I+H \cdot T+G \cdot T 2}\right)^{2}-\frac{C-n+B \cdot T+A \cdot T 2}{I+H \cdot T+G \cdot T 2}\right]^{0,5}
\end{aligned}
$$

using the coefficients given in Table 4 .

\section{Experimental results}

\subsection{Performance test and validation}

The modified standard apparatus was validated with pure $n$ pentane [6]. Figure 10a, b show plots of recent literature data [17] and the validation measurement series at $314.4 \mathrm{~K}$ and $350.4 \mathrm{~K}$ on copper tubes [6]. The data is in reasonable agreement. Further measurements with pure $n$-pentane are not possible since cleaning the apparatus is not possible with reasonable effort once first measurements with PDMS are carried out. However, recently conducted measurements with a high share of $n$-pentane (93 wt.-\%) show consistent results to earlier measurements [6] with pure $n$-pentane.

\subsection{Analysis of the influence of forced convection on the heat transfer and of the stability of the composition}

The target of this work is to investigate pool boiling in highly viscous mixtures. Thus, the effect of forced convection on

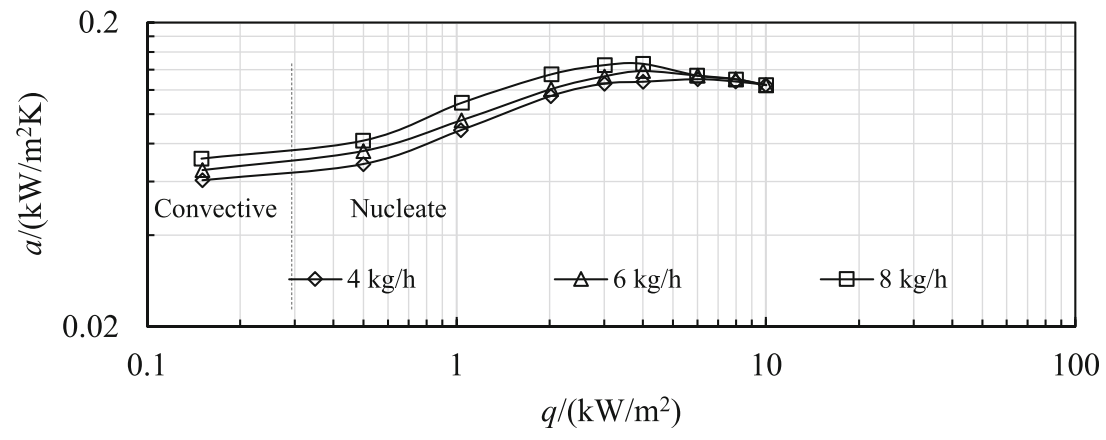


Fig. $13 \log , \log \alpha(q)$ - diagram for boiling heat transfer of $95 \mathrm{wt}$.$\%$ PDMS M10k in $n$-pentane at $T=381 \mathrm{~K}$ at different mass flows on a polished copper tube

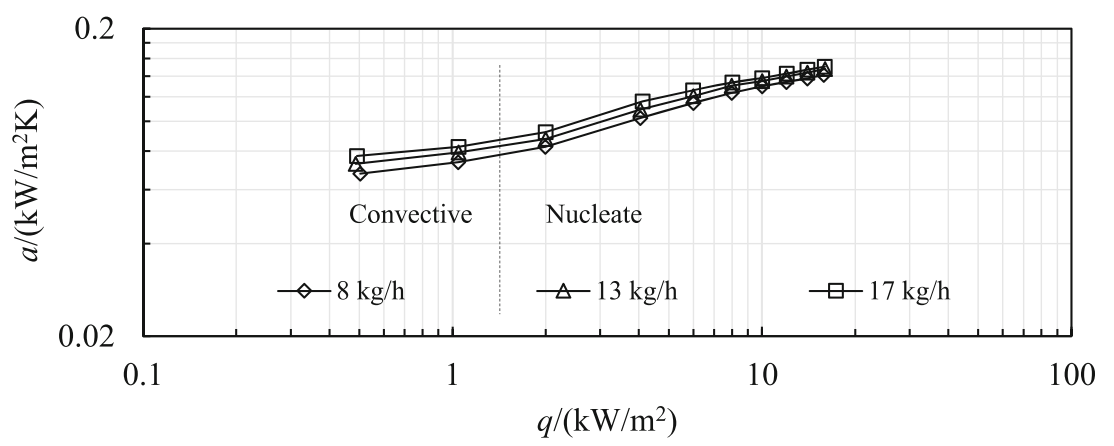

heat transfer needs to be eliminated, or at least minimized. However, the condensed $n$-pentane needs to be remixed with the depleted PDMS to keep the composition in the evaporator stable. Binary PDMS rich $/ n$-pentane depleted mixture is pumped from the evaporator, remixed with the condensate, and passes a static mixer and the refractometer before it is transported back into the evaporator. This process causes a flow in the evaporator (forced convection). The maximum condensate rate is calculated to be $1.11 \mathrm{~kg} / \mathrm{h}[10,18]$. To ensure that remixing is complete with a composition close to the average bulk liquid composition composition and that there is no need to change the settings of the gear pump (see Figs. 1 and 2) during a measurement series, the flow of PDMS rich / $n$-pentane depleted mixture has to be set to at least $4 \mathrm{~kg} /$ h. For different mass flows the resulting average velocities at the entrance into the pool and on the test tube level are listed in Table 5 , assuming a medium density of $\rho=700 \mathrm{~kg} / \mathrm{m}^{3}$.

To find the ideal compromise between a constant composition and a minimum influence of circulation, investigations were carried out with several mixtures at different isotherms. The dashed line in the diagrams indicates the change in the dominant heat transport mechanisms from convective boiling to nucleate boiling.

Figures 11 and 12 show measured heat transfer coefficients in a fluid with 73 wt.-\% PDMS M100k at $316 \mathrm{~K}$ and $349 \mathrm{~K}$. The impact of the flow decreases at high heat fluxes and with an increasing slope $\partial \alpha / \partial q$. In mixtures with $\mathrm{M} 10 \mathrm{k}$ forced convection increases the heat transfer coefficient as well. Figure 13 shows measured data for a fluid with 95 wt.- $\%$ of PDMS M10k at $381 \mathrm{~K}$ at three different mass flows. At increased mass flow, the heat transfer coefficient is enhanced by $6 \%$ to $14 \%$ compared to the measured heat transfer coefficients at $4 \mathrm{~kg} / \mathrm{h}$.

Though flow velocities are very small, all measurements show that forced convection increases the heat transfer coefficient regardless to the heat flux; the circulation rate should be chosen as low as possible. To find out if the lowest considered mass flow $(4 \mathrm{~kg} / \mathrm{h})$ guarantees a stable composition of the mixture, the compositions calculated based on refractive index and temperature need to be analyzed. Figure 14 shows the heat transfer coefficients in a fluid with 84 wt.- $\%$ M10k at $323 \mathrm{~K}$ at four different mass flows. Figure 15 shows the corresponding scatter in the measured composition of the mixture.

The measured composition of the mixture is stable with a scatter of less than $0.5 \%$. The mean value of the measured composition does not change by more than 0.1 wt.- $\%$ for different mass flows. The scatter of the measured compositions is not higher at low mass flows. This proves that a mass flow of $4 \mathrm{~kg} / \mathrm{h}$ is sufficient for stable remixing of condensate and $n$-pentane depleted mixture. A similar behavior was observed for several other mixtures and temperatures. Lower mass flows could not guarantee a sound remixing and constant composition at high heat fluxes. Thus, the mass flow of PDMS rich $/ n$-pentane depleted mixture was set to $4 \mathrm{~kg} / \mathrm{h}$ in most experiments to achieve the best possible compromise between a reduced impact of forced convection and stable composition in the pool.
Fig. $14 \log , \log \alpha(q)$ - diagram for boiling heat transfer of $84 \mathrm{wt}$. $\%$ PDMS M10k in $n$-pentane at $T=323 \mathrm{~K}$ at different mass flows on a polished copper tube

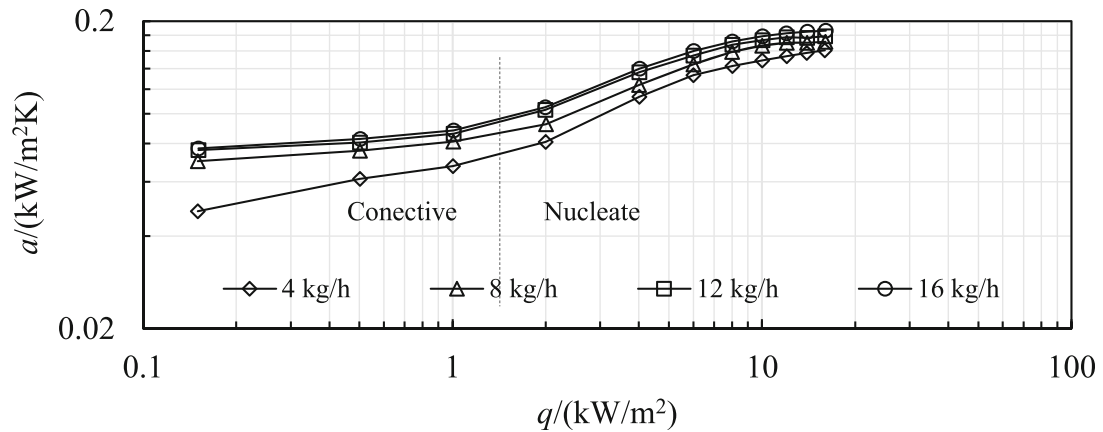


Fig. 15 Scatter in measured PDMS fractions at different mass for a system with $84 \mathrm{wt} .-\%$ PDMS M10k in $n$-pentane at $323 \mathrm{~K}$ for experiments with varying heat fluxes applied via a polished copper tube

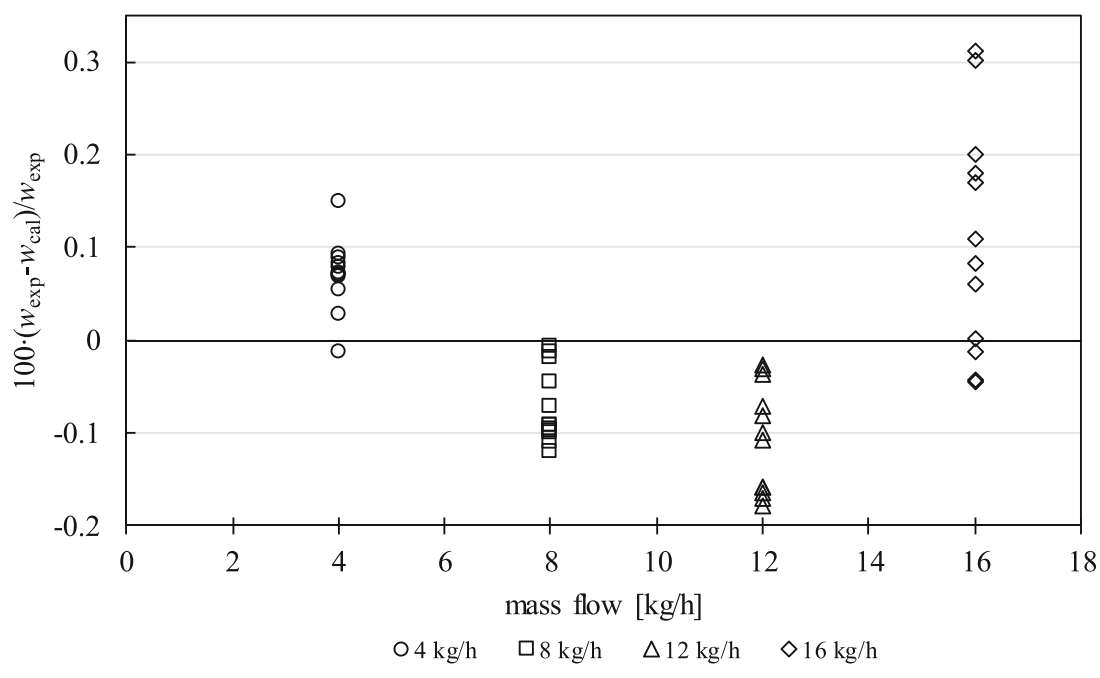

\section{Conclusion}

A modified so-called standard apparatus was presented in this article. It was developed to measure heat transfer coefficients in mixtures in a viscosity range from $0.2 \mathrm{mPa} \cdot \mathrm{s}$ up to $1000 \mathrm{~Pa} \cdot \mathrm{s}$ in a temperature range from 273 to $423 \mathrm{~K}$. The estimated total uncertainty of the heat transfer coefficient is $\Delta \alpha / \alpha=16 \%(k=2)$. Mixtures of PDMS and $n$-pentane were chosen as model fluids. The change in viscosity with respect to the temperature and to the share of $n$-pentane was calculated and plotted. The filling process and the measurement procedure were described. The high viscosities of the fluids inhibit the heat transport and cause very high temperatures on the test tube surface. To avoid damage of the test tube, the construction of the tubes was adapted. Instead of soft solder thermal grease was used to fill the grooves for the installed thermoelements. Thermal grease does not melt until very high temperatures are reached. The investigated fluid mixtures were produced gravimetrically, but the knowledge of the exact composition of the mixture circulated in the apparatus is crucial. A refractometer is used to measure the refractive index of the mixture. Compositions were calculated with an empirical correlation relating the composition to the measured refractive index and to the temperature, which is based on data measured for this work. $\mathrm{N}$-pentane evaporates on the test tube and is remixed with the depleted PDMS to guarantee a stable composition during a measurement series. The remixing process causes a disturbing flow on the test tube, which enhances the heat transfer coefficient. Investigations have been presented to evaluate the impact of the flow and to find the best compromise between a stable composition and a minimized impact of the flow. To test the performance of the modified standard apparatus, heat transfer measurements with pure $n$-pentane were carried out; the results are in good agreement with literature data. Results of systematic measurements covering a wide range of temperatures and compositions, PDMS with different viscosities, and different heating surfaces are published in parallel in a second article [7].
Acknowledgements The authors are grateful to all who contributed to this work, especially to Prof. A. Luke and her team at the University of Kassel. We thank the Deutsche Forschungsgemeinschaft (DFG) for funding this project under Grant No. SP 507/6-2. We are thankful to Stanislaw Derksen for supporting the present project within the scope of his bachelor's and master's theses and to Jan Humbach, a student research assistant. Moreover, we thank Christian Gramann and the team of the mechanical workshop at the Ruhr University Bochum for their support.

Funding Open Access funding enabled and organized by Projekt DEAL.

\section{Compliance with ethical standards}

Conflict of interest On behalf of all authors, the corresponding author states that there is no conflict of interest.

Open Access This article is licensed under a Creative Commons Attribution 4.0 International License, which permits use, sharing, adaptation, distribution and reproduction in any medium or format, as long as you give appropriate credit to the original author(s) and the source, provide a link to the Creative Commons licence, and indicate if changes were made. The images or other third party material in this article are included in the article's Creative Commons licence, unless indicated otherwise in a credit line to the material. If material is not included in the article's Creative Commons licence and your intended use is not permitted by statutory regulation or exceeds the permitted use, you will need to obtain permission directly from the copyright holder. To view a copy of this licence, visit http://creativecommons.org/licenses/by/4.0/.

\section{References}

1. Wienecke M, Luke A, Gorenflo D, Span R (2005) Flow boiling of highly viscous fluids in a vertical annular tube. Chem Eng Res Des. https://doi.org/10.1205/cherd.03334

2. Liesenfelder U, Kohlgrüber K, Wienecke M, Span R (2006) Flow boiling of a highly viscous polymer solution. International Heat Transfer Conference 13 (IHTC 13), Sydney. https://doi.org/10. 1615/IHTC13.p28.30 
3. Mohrlok K, Spindler K, Hahne E (2001) The influence of a low viscosity oil on the pool boiling the transfer of the refrigerant R507. IJR. https://doi.org/10.1016/S0140-7007(00)00068-2

4. Spindler K, Hahne E (2009) The influence of oil on nucleate pool boiling heat transfer. Heat Mass Transf. https://doi.org/10.1007/ s00231-007-0321-0

5. Wang C, Hafner A, Kuo C, Hsieh W (2012) An overview of the effect of lubricant on the heat transfer performance on conventional refrigerant R-744. Renew Sust Energ Rev. https://oi.org/10.1016/ j.rser.2012.04.054

6. Buljina I (2010) Entwicklung und Aufbau zweier Siedeapparaturen zur Untersuchung des Wärmeübergangs weitsiedender binärer niedrig- und hochviskoser Gemische. Dissertation, Department of Mechanical Engineering, Ruhr University Bochum

7. Fleer A, Richter M, Span R (2021) Systematic heat transfer measurements in highly viscous binary fluids. Heat Mass Transf. Under Review

8. Gorenflo D, Goetz J, Bier K (1982) Proposal of a standard apparatus for the measurement of pool boiling heat transfer. Wärme- und Stoffübertragung 16:69

9. Datasheet Bayer Silicone Baysilone Öle M, Edition 12.97 (1997). https://dcproducts.com.au/wp-content/uploads/2020/12/ BayerBaysiloneFluidsBrochure.pdf. Accessed 31 Jan 2021

10. Thol M, Uhde T, Lemmon EW, Span R (2020) Fundamental equations of state for hydrocarbons part I n-pentane to be published. Available in RefProp 10.0
11. Liesenfelder U (2010) Strömungssieden hochviskoser Polymerlösungen. Dissertation, Ruhr University Bochum

12. Luke A (2006) Preparation, measurement and analysis of the microstructure of evaporator surfaces. Int J Therm Sci. https://doi.org/ 10.1016/j.ijthermalsci.2005.03.018

13. DIN EN ISO 4287:2010-07 geometrical product specifications (GPS) - surface texture: profile method - terms, definitions and surface texture parameters. 2010-07

14. Flexim (2019) Flexim brochure flexim Piox R - chemical design. Accessed 16 Dec 2019

15. Gernert J (2007) Aufbau einer Umlaufapparatur zur Konzentrationsbestimmung von hochviskosen Gemischen. Student research project, Paderborn University

16. Wedeking M (2007) Konzentrationsmessung hochviskoser Gemische. Student research project, Paderborn University

17. Kotthoff S (2014) Zum Einfluss von Fluid- und Heizflächeneigenschaften auf Wärmeübergang und Blasenbildung beim Sieden. DKV-Forschungsbericht Nr. 84, Dissertation, Paderborn University

18. Fleer A (2019) Wärmeübergang beim Behältersieden von hochviskosen (n-Pentan + Polydimethylsiloxan) - Gemischen am horizontalen Rohr. Dissertation, Ruhr University Bochum

Publisher's note Springer Nature remains neutral with regard to jurisdictional claims in published maps and institutional affiliations. 